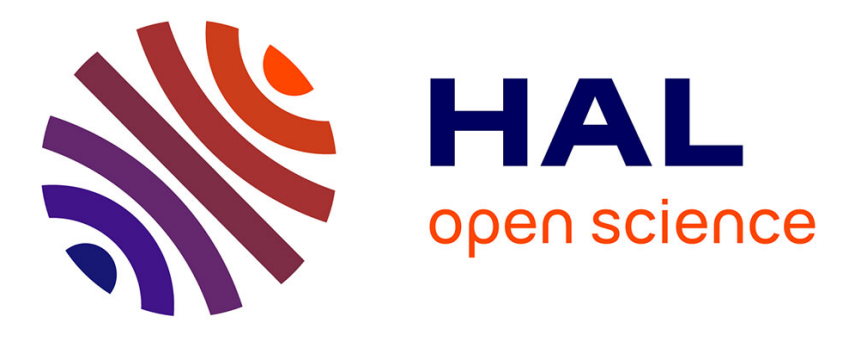

\title{
Characteristics of HIV-1 Non-B Subtype Infections in Northwest Poland
}

Milosz Parczewski, Magdalena Leszczyszyn-Pynka, Dorota Bander, Anna Urbańska, Grzegorz Stańczak, Anna Boroń-Kaczmarska

\section{To cite this version:}

Milosz Parczewski, Magdalena Leszczyszyn-Pynka, Dorota Bander, Anna Urbańska, Grzegorz Stańczak, et al.. Characteristics of HIV-1 Non-B Subtype Infections in Northwest Poland. Journal of Medical Virology, 2010, 82 (8), pp.1306. 10.1002/jmv.21797 . hal-00552410

\section{HAL Id: hal-00552410 https://hal.science/hal-00552410}

Submitted on 6 Jan 2011

HAL is a multi-disciplinary open access archive for the deposit and dissemination of scientific research documents, whether they are published or not. The documents may come from teaching and research institutions in France or abroad, or from public or private research centers.
L'archive ouverte pluridisciplinaire HAL, est destinée au dépôt et à la diffusion de documents scientifiques de niveau recherche, publiés ou non, émanant des établissements d'enseignement et de recherche français ou étrangers, des laboratoires publics ou privés. 


\section{Characteristics of HIV-1 Non-B Subtype Infections in Northwest Poland}

\begin{tabular}{|c|c|}
\hline Journal: & Journal of Medical Virology \\
\hline Manuscript ID: & JMV-09-1596.R1 \\
\hline Wiley - Manuscript type: & Research Article \\
\hline $\begin{array}{r}\text { Date Submitted by the } \\
\text { Author: }\end{array}$ & 24-Feb-2010 \\
\hline Complete List of Authors: & $\begin{array}{l}\text { Parczewski, Milosz; Pomeranian Medical University, Department of } \\
\text { Infectious Diseases } \\
\text { Leszczyszyn-Pynka, Magdalena; Pomeranian Medical University, } \\
\text { Department of Infectious Diseases } \\
\text { Bander, Dorota; Pomeranian Medical University, Department of } \\
\text { Infectious Diseases } \\
\text { Urbańska, Anna; Pomeranian Medical University, Department of } \\
\text { Infectious Diseases } \\
\text { Stańczak, Grzegorz; Hospital for Infectious Diseases, Molecular } \\
\text { Diagnostics Laboratory, } \\
\text { Boroń-Kaczmarska, Anna; Pomeranian Medical University, } \\
\text { Department of Infectious Diseases }\end{array}$ \\
\hline Keywords: & Subtype D, HIV subtypes, phylogenesis, HIV transmission, Poland \\
\hline
\end{tabular}

\section{今) ScholaroNE" \\ Manuscript Central}


Neighbor-joining tree showing phylogenetic relationships of subtype B isolates to the HIV-1 M group reference strains $25 \times 21 \mathrm{~mm}(600 \times 600 \mathrm{DPI})$ 


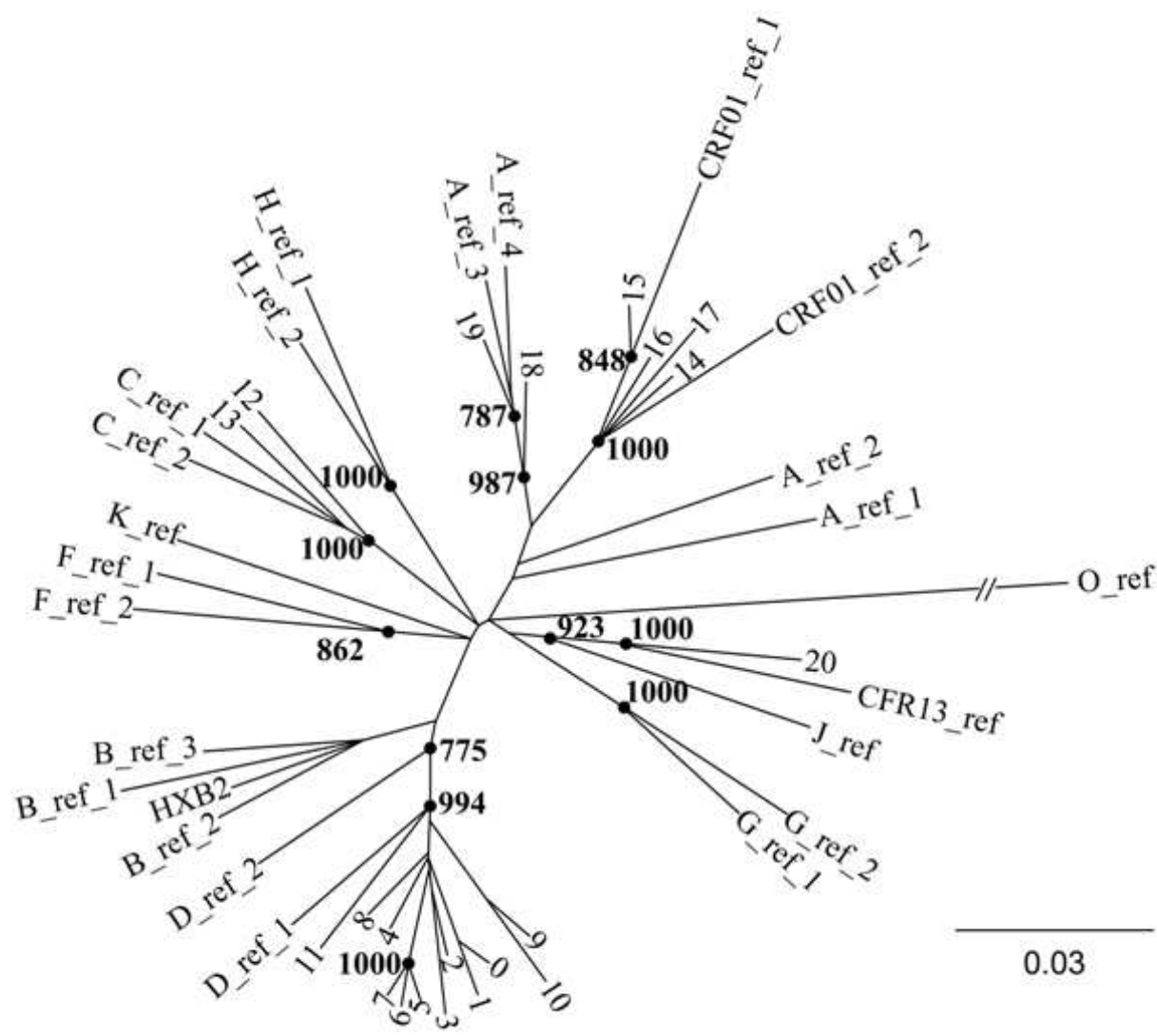

Neighbor-joining tree showing phylogenetic relationships of non-subtype B isolates to the HIV-1 M group reference strains $27 \times 25 \mathrm{~mm}(600 \times 600 \mathrm{DPI})$ 
Fig 2

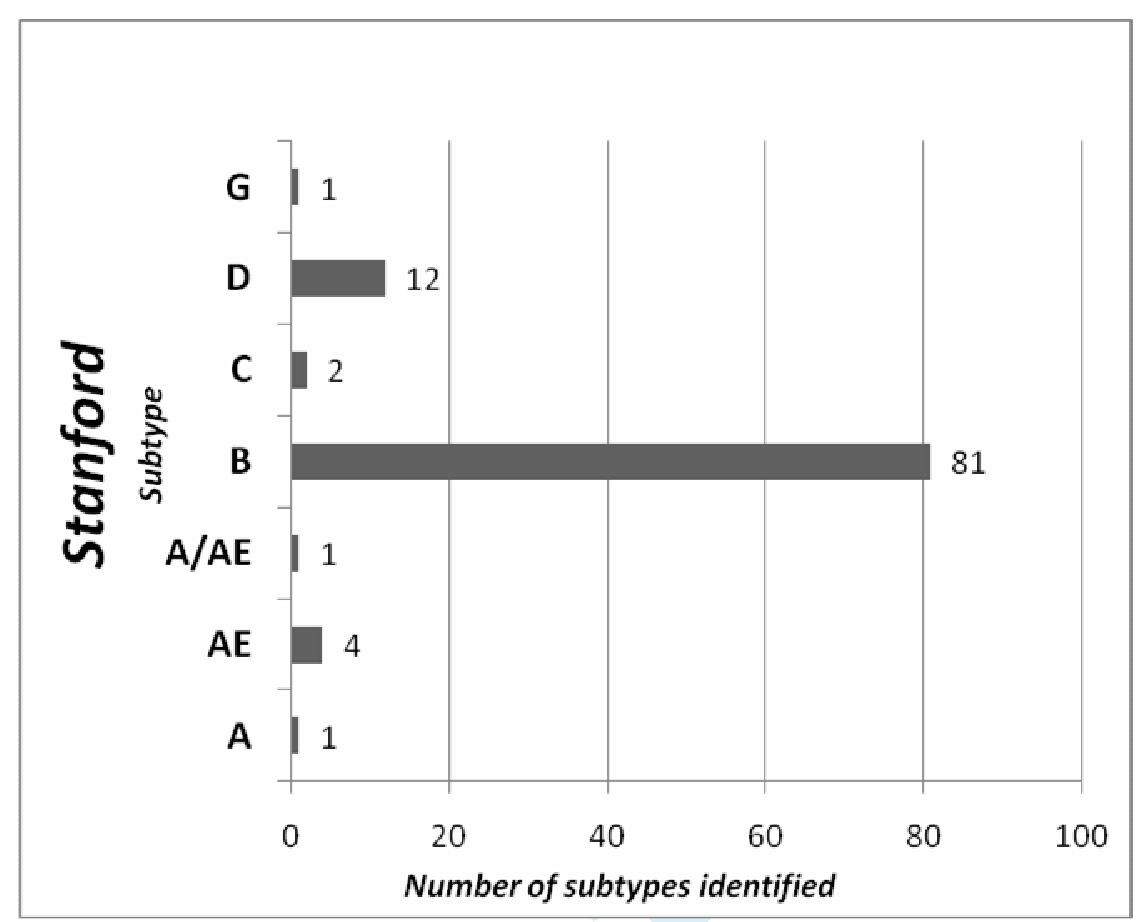

A

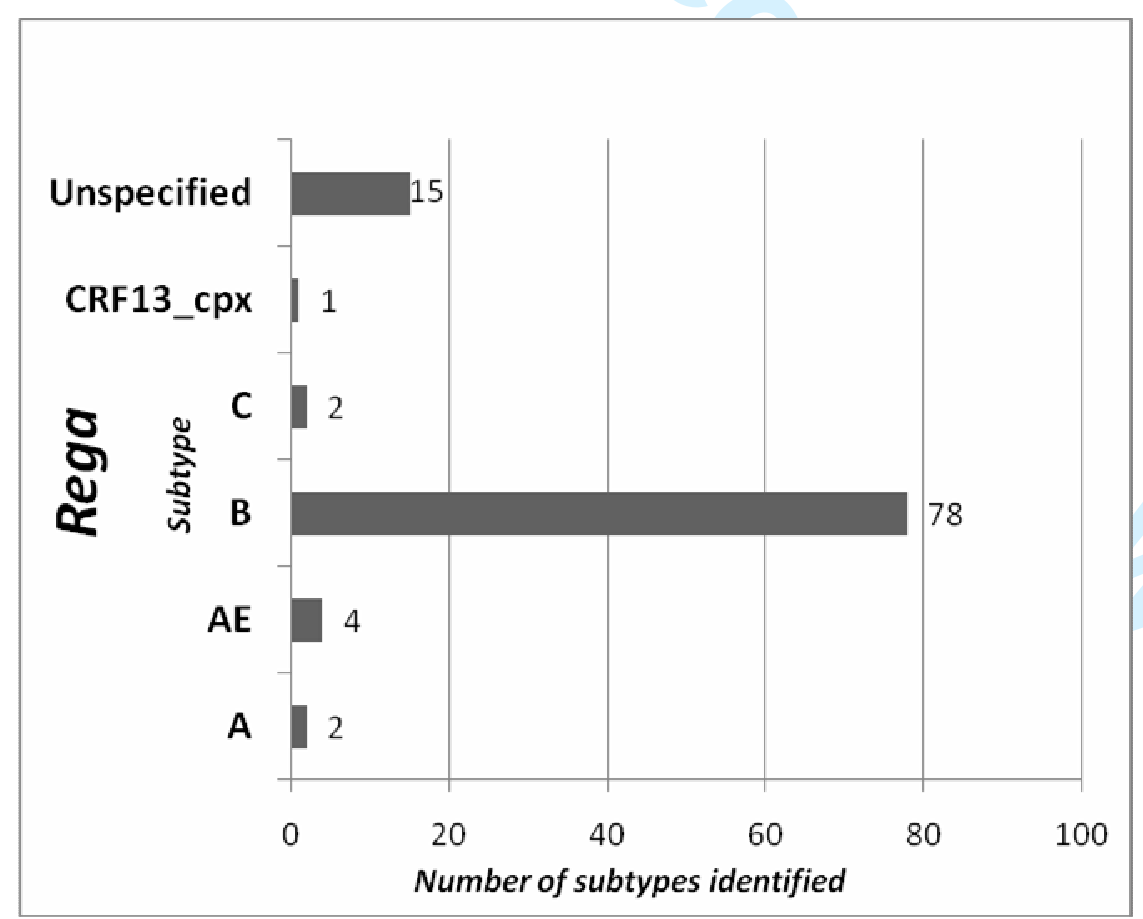

B 


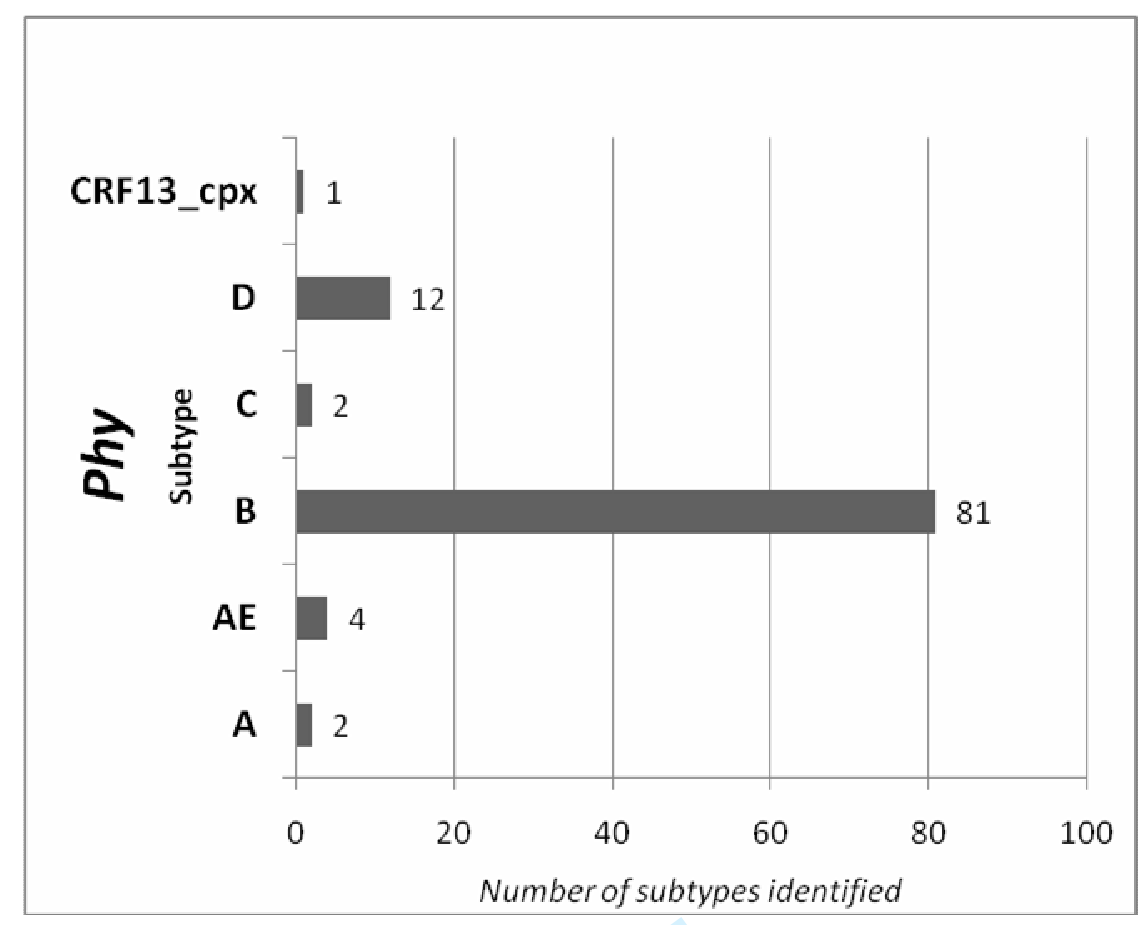

C 


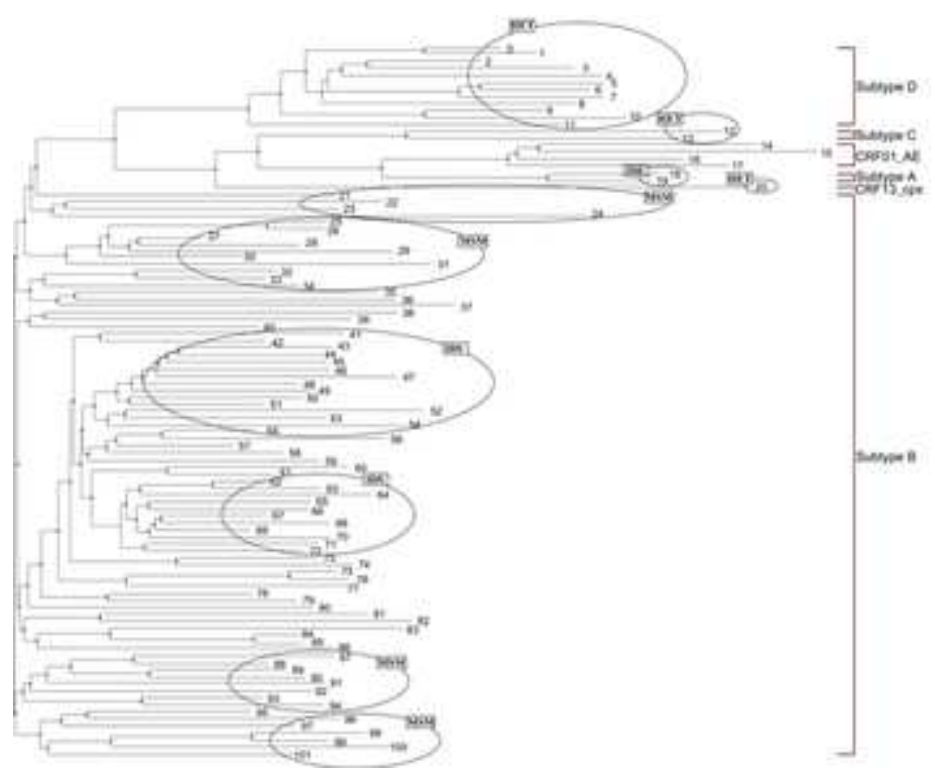

Phylogenetic tree reconstruction $15 \times 12 \mathrm{~mm}(600 \times 600 \mathrm{DPI})$ 


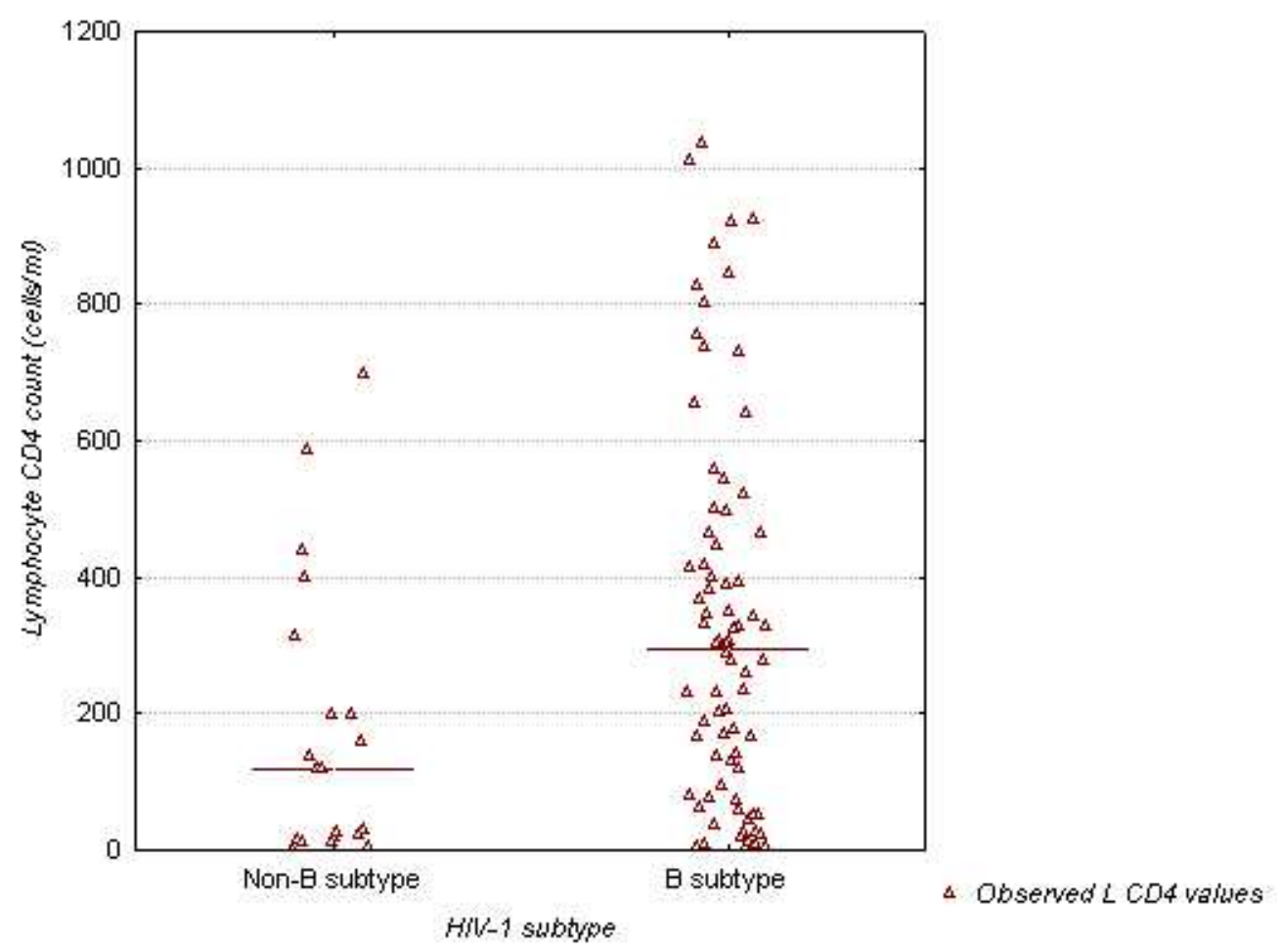

Baseline CD4+ lymphocyte counts in the analysed groups. $137 \times 103 \mathrm{~mm}(96 \times 96 \mathrm{DPI})$ 


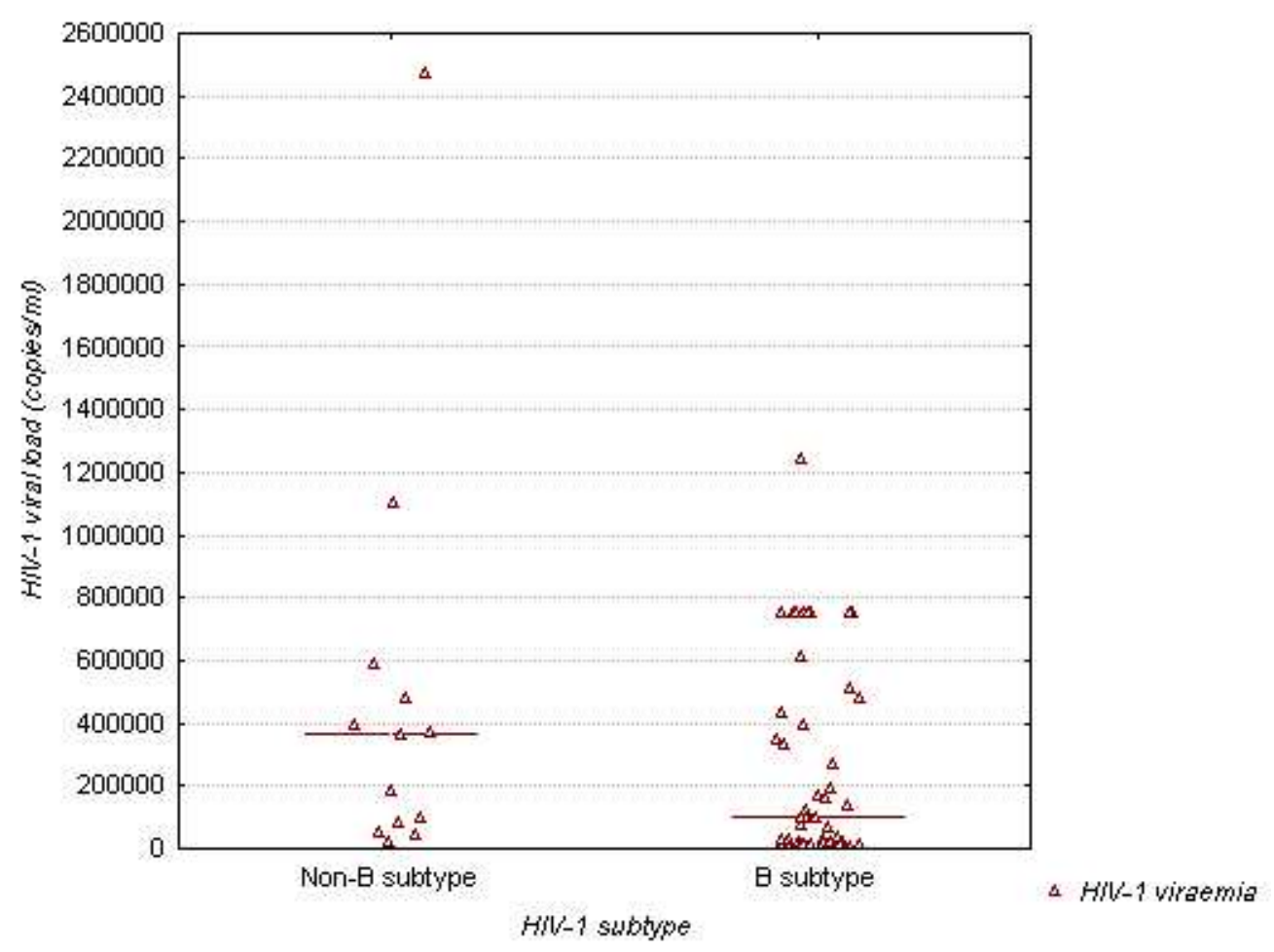

Baseline HIV-1 viral loads in the analysed groups $137 \times 103 \mathrm{~mm}(96 \times 96 \mathrm{DPI})$ 
1 Title: Characteristics of HIV-1 Non-B Subtype Infections in Northwest Poland.

2

3 Authors: Miłosz Parczewski ${ }^{1}$, Magdalena Leszczyszyn-Pynka ${ }^{1}$, Dorota Bander ${ }^{1}$, Anna Urbańska ${ }^{1}$,

4 Grzegorz Stańczak², Anna Boroń-Kaczmarska

$5{ }^{1}$ Department of Infectious Diseases and Hepatology, Pomeranian Medical University, Szczecin, Poland

$6{ }^{2}$ Molecular Diagnostics Laboratory, Hospital for Infectious Diseases, Warsaw, Poland

7

8 Running head: HIV-1 Non-B subtypes in Northwest Poland

9

10 Correspondence to:

11 Miłosz Parczewski M.D. Ph.D.

12 Pomeranian Medical University,

13 Department of Infectious Diseases and Hepatology,

14 Arkońska 4

15 71-455 Szczecin, Poland

16 Tel. 0048918139456 , Fax. 0048914316242

17 e-mail: mparczewski@yahoo.co.uk 


\section{Abstract}

The number non-B subtype HIV-1 infections in Europe have been increasing even though major

regional differences have been observed. This trend was investigated in northwestern Poland using

sequence and epidemiological data from a cohort of 102 HIV-1-infected patients from Szczecin,

Poland. HIV-1 subtypes were defined by phylogenetic analysis of viral reverse transcriptase- and protease-partial coding regions and results were compared with online subtyping by Standford and

REGA tools. Subtype analysis using on-line subtyping methods produced varying results if compared to phylogenesis, with concordant variant assignment obtained for $98 \%(100 / 102)$ of sequences by Stanford and $85 \%(87 / 102)$ by REGA. In the population studied, non-B subtype infections comprised from this region. $(9.5 \%, n=2)$ and the CRF13_cpx recombinant isolate $(4.8 \%, n=1)$. Patients carrying non-B subtypes were predominantly heterosexuals with high percentage (57\%) of women observed in the group. All HIV-1 non-B women were Caucasian with majority (83\%) of infections acquired in Poland, however among 12 travelers included in the study a higher proportion of non-B infections was noted $(50 \%$, $p=0.01)$. Moreover, lower baseline lymphocyte CD4 counts $(p=0.01)$, higher baseline HIV-1 viraemia $(p=0.08)$ and a more advanced stage of the disease $(p=0.03)$ were observed among individuals infected with non-B subtypes. The data indicated that the proportion of HIV-1 non-B subtype infections was higher than previously reported in Poland consisting of a high subtype D prevalence. Furthermore, subtype D transmission occurred primarily between heterosexual Caucasian individuals

Key Words: HIV subtype D; non-B subtypes; HIV transmission, phylogenetic analysis, Poland 


\section{INTRODUCTION}

41 The transmission of major (M) and non-major (N) groups of Human Immunodeficiency Virus (HIV) from chimpanzees, along with outlier $(0)$ group viruses of likely gorilla ancestry, were the initial steps in the evolution of the human HIV epidemic [Keele et al., 2006, Van Heuverswyn F et al. 2006].

Furthermore, high reverse transcriptase error rates have resulted in additional diversification into different HIV strains [Rambaut et al., 2004]. Sequence-based research has identified a range of subtypes (clades) and recombinant forms within the most common HIV-1 M group. Subtype $\mathrm{C}$ is the most common clade worldwide (approximately $50 \%$ of all HIV-1 clades) and is found predominately in Sub-Saharan Africa and the Indian subcontinent whereas clades A, D and CRF01_AE are observed less frequently $(12 \%, 6.5 \%$, and $2.5 \%$, respectively). Circulating recombinant forms (CRFs) including CRF01_AE and CRF02_AG have been reported mainly in East-Asia and West Africa, while novel recombinants continue to be identified worldwide [Taylor, Hammer, 2008]. In present time Europe, subtype B remains the most common clade identified, particularly among Caucasians, however, subtype B represents only $10 \%$ of global HIV-1 infections [Paraskevis et al., 2009]. In addition, injection drug use and male homosexual contacts are commonly associated with subtype B infections. occur . In contrast, transmission of non-B subtypes is most common between heterosexuals [Kantor et al., 2005] and in Poland, this pattern is similar with respect to subtype B infections predominating in injection drug users and homosexuals [Chaix et al., 2003, Stańczak et al., 2007]. However, the number of non-B subtype infections among Caucasians has been increasing. The current reported prevalence of non-B subtype infections in Poland is $11.2 \%$ with more than half of these belonging to the $C$ and $D$ subtypes and the CRF03_AB; CRF05_DF and CRF01_AE recombinant clades [Stańczak et al., 2007]. Although most antiretroviral studies and observational cohorts have analyzed populations comprised predominantly of clade B-infected individuals, others have indicated that virological and immunological treatment responses are similar regardless of the subtype [Bocket et al., 2005; Holguin et al., 2006]. 
65

66

67

68

69

The city of Szczecin, located in northwestern Poland, has an HIV-1 incidence of 0.35/100,000 compared to an incidence rate of $0.47 / 100,000$ nationwide [Czarkowski et al., 2007]. In this region, intravenous drug use used to be the predominant HIV transmission route, however, sexually transmitted infections between Caucasians now predominate (immigrants comprise less than $1 \%$ of observed HIV infection cases). Since the port of Szczecin is strategically situated on the PolishGerman border, HIV infections transmitted from sailors and young homosexual males travelling to Germany are common (internal center data) and HIV infections in Poland (and in the region) are more prevalent among males. However, the number of infected women among newly diagnosed subjects has been increasing recently (from 21\% in 2006 to $24 \%$ in 2008) (National Institute of Public Health, data available on-line www.pzh.gov.pl/oldpage/epimeld/index_p.html).

In this study, HIV-1 transmission data is correlated with demographic and epidemiologic data from a northwestern Polish cohort. HIV isolates obtained from patient plasma samples were subtyped and subjected to phylogenetic reconstruction analyses based on partial protease and reverse transcriptase sequences. This analysis revealed a larger than expected number of non- $B$ subtype isolates, suggesting a change in the epidemiology of HIV infection. Awareness of the infecting strains in respective populations will be critical for the administration of appropriate antiviral interventions. 
83

84

85

86

87

\section{METHODS}

\section{Population}

This study analyzed HIV-1 sequence data from 102 patients ( 73 male, 29 female) that were followed-up routinely at the Department of Infectious Diseases and Hepatology, Pomeranian Medical University, Szczecin, Poland. With the exception of one patient, all were Caucasian and acquired their infections sexually $(n=68)$ or by injection drug use $(n=34)$. HIV sequencing was performed in patients failing antiretroviral regimens ( $n=37)$ and in patients with newly diagnosed infections as a means of identifying new subtype strains or newly transmitted drug resistant strains $(n=65)$. The mean age of the patients was 38.7 years (median $36 \pm 9,1$, range $23-67$ years).

\section{Sample Collection and Analysis}

Plasma samples collected from patients between 1996-2009 were stored at $-80^{\circ} \mathrm{C}$ and analyzed retrospectively. HIV RNA extraction (with subsequent sequencing of the protease and reverse transcriptase genes) was performed using a 2.8 Viroseq HIV-1 Genotyping System (Abbott Molecular, Illinois, USA) and the Trugene Genotyping system (Bayer HealthCare, Tarrytown, USA) according to the manufacturer's protocols. Fasta sequences ( $p o$ l sequence lengths of 1297-1302 base pairs [bp]) obtained in the process were used in this study. All sequences were aligned using the Clustal X2.0.10 software (www.clustal.org) with manual editing by Bioedit (version 7.0.5., Ibis Therapeutics, Carlsbad, USA). Phylogenetic analyses were performed using the Phylip Package version 3.69 (University of Washington, Department of Genome Sciences, USA) with evolutionary distances estimated using DNADIST (Kimura two-parameter method) and bootstrapping carried out using SEQBOOT (1000 replicates). Phylogenetic reconstructions were performed by NEIGHBOR (neighbor-joining method) for tree construction. Trees were visualized with TreeView (version 1.6.6, University of Glasgow, UK) or Tree Figure Drawing Tool (version 1.2.2, University of Edinburgh, UK). 
108 For phylogeny-based subtype determination, a selection of reference sequences listed in the HIV 109 Sequence Compendium 2009 (Los Alamos National Laboratory Los Alamos, U.S.A. 110 http://www.hiv.lanl.gov, two sequences for each subtype and at least one for each CRF), as well as 111 sequences from Central Europe for two common subtypes (gen-bank IDs AF34733, DQ823362 112 (subtype B), DQ823357, EF545108 (Subtype A)) were used.

113 Tree topology analysis was used to assign subtypes based on a high level of bootstrap 114 support (>700) for each subtype or CRFs examined. Additionally, subtype determinations were 115 performed using two rapid on-line tools: the REGA genotyping 2.0 tool 116 (http://bioafrica.mrc.ac.za/rega-genotype/html/subtypinghiv.html) and the Stanford HIV database 117 (http://hivdb.stanford.edu) for verification and comparison.

\section{Statistics}

Statistical analyses for nominal variables were performed using Chi-square and Fisher's exact 121 tests for small groups using EPI6 Statcalc software (Department of Mathematics, University of 122 Louisiana-Lafayette, Lafayette, LA, USA); for nominal variables, the U-Mann Whitney test was 123 performed using Statistica software (Statsoft, Tulsa, USA). P-values of $<0.05$ were considered 124 significant; with values in the range of 0.1-0.051 regarded as borderline statistically significant. 


\section{RESULTS}

Using phylogeny-based subtyping methods it was possible to assign an HIV subtype to each isolate examined with bootstrap support of $100 \%$. Two phylogenetic trees, drawn separately for B and non-B subtypes are shown (Fig. 1 A,B). Subtype $B$ infections were the most common ( $n=81 ; 79 \%)$, although the prevalence of non-B strains was $21 \%$ (21/102). Of these non-B strain infections, $57 \%$ ( $n=12)$ were subtype D, 19\% were CRF01_AE $(n=4), 9.5 \%$ were $A$ and C clade infections $(n=2) ; 4.8 \%$ were of the CRF13_cpx recombinant variant $(n=1)$. Subtype analysis results using on-line subtyping methods produced varying results. The REGA genotyping tool was unable to assign a subtype to all subtype D and three subtype B isolates. On the other hand, analysis using the Stanford HIV database identified one case to be infected with subtype A/CRF01_AE recombinant (protease-clade A, reverse transcriptase - CRF01_AE) that were assigned as subtype A by both phylogenetic analysis and REGA while a strain classified as CRF13_cpx was classified as subtype G by the Stanford database (Figure 2). For each patient examined, the route of transmission was identified: 33\% (34/102) resulted from male homosexual contacts, $31 \%(32 / 102)$ by injection drug use and $28 \%(29 / 102)$ were heterosexual transmissions. In $7 \%(7 / 102)$ of cases it was not possible to define equivocally the transmission route (patients reported both unprotected heterosexual and homosexual sexual contacts or unprotected sexual contacts combined with injection drug use), therefore a mixed route of infection was assigned.

Clustering of sequences with concordant transmission routes was noted as indicated in Figure 3. Infections with clade C, D or CRF13_cpx variants were acquired exclusively through heterosexual contact while subtype A- or CRF01_AE-infected patients acquired their infections as a consequence of injection drug use. Two patients presented with a variant CRF01_AE infection acquired through heterosexual contact (from Cambodia and Germany). A significant number of patients infected as a consequence of heterosexual exposure were infected primarily with non-B subtypes (versus B subtype-infected patients) $(p<0.01,95 \% \mathrm{Cl}[0.04-0.16]$, OR: 0.04) with a significantly higher number of women presenting with this type of infection $(p=0.01,95 \% \mathrm{Cl}[0.06-06]$, 
151 OR: 0.2). All women with non-B subtype infections were Caucasian and the majority (83\%) of 152 infections were acquired in Poland. Of these, only two reported commercial sex work with the 153 remaining admitting to casual, infrequent heterosexual contacts. A total of 12 cases reported risky 154 sexual behavior outside of Poland; four patients were professional sailors reporting exposure in 155 Germany, one in the UK, Cambodia and Vietnam, respectively. Among travelers, non-B subtype 156 infections (four CRF01_AE cases, one from each clade D and CRF13_cpx cases) were statistically 157 greater $(n=6,50 \%, p=0.01$, Fisher's exact test) compared to the rest of the cohort.

$158 \quad$ Most of HIV-diagnosed patients in the study $(61 / 102,59.8 \%)$ were either symptomatic or in 159 the AIDS stage. Baseline lymphocyte CD4 counts below 350 cells/ $\mu$ l were noted in 64 (62\%) 160 individuals. Significantly lower baseline lymphocyte CD4 counts $(p=0.01)$, higher baseline HIV-1 161 viremia (borderline statistical significance, $p=0.08$ ) and a more advanced stage of the disease (AIDS 162 cases notably more common, $\mathrm{p}=0.03$ ) were observed among individuals infected with non-B 163 subtypes. Patient characteristics are described in Table I, with distribution of lymphocyte CD4 counts 164 and viral load levels among subtype B and non-subtype B groups presented in Figures 4 and 5. 


\section{DISCUSSION}

This study assessed the HIV subtypes present in a cohort of patients from Szczecin, Poland.

HIV strains were subtyped based on protease and reverse transcriptase sequences using three

distinct typing tools. Subtyping results from the two on-line rapid tools (REGA genotyping 2.0 and the

Stanford HIV database) were compared with phylogenetic analysis. This comparison revealed that

172 the REGA tool was not able to classify equivocally subtype D strains in all cases, however, it classified 173 correctly the CRF13_cpx recombinant strain assigned to subtype G by the Stanford database. The 174 subtyping analysis carried out using REGA matched the A, CRF01_AE and C clades in accordance with 175 the phylogenetic analysis results, while the Stanford analysis inappropriately classified one subtype A 176 sample as an A/CRF01_AE recombinant (Figure 2A-C). However, the Stanford database tool correctly assigned all B clade samples (100\%) compared to the $96.2 \%$ rate observed using the REGA tool. The failure to identify subtype B strains in three cases using the REGA tool was probably due to shorter sequence lengths. As described previously [Holguín et al., 2008], also in this study misclassification of some non-B subtypes was observed when using the rapid on-line tools, which reinforces the need to use phylogenetic analyses to confirm subtyping results.

To date, the HIV subtype distribution in Poland was similar to that reported for Western

Europe, with subtype B strains being the cause of the majority of infections [Hemelaar et al., 2006,

Stańczak et al., 2006]. However these data were based on data from rapid subtyping tools in the 185 absence of phylogenetic analyses. In the population described in this study, the number of non-B 186 subtypes was higher than the published national average reported between $1996-2004$ (21\% versus 187 11.2\%) [Stańczak et al., 2006]. Of the non-B variants identified in this study, subtype D was the most common (57\%). Furthermore, among the patients examined, there were a surprisingly higher 189 percentage of $C$ and $D$ clades among Polish women infected as a consequence of heterosexual exposures (75\%). 
Until this study was carried out, it was believed that non-B transmissions between heterosexual Caucasians occurred only infrequently [Böni et al., 1999; Ramirez-Piedad et al., 2009, Thomson et al., 2007], however, the number of new infections resulting from non-B clades is increasing in this population [Holguín et al., 2008]. In this study all but one infection with subtype D was related to heterosexual transmission among Caucasians and such spread of this non-B clade strain has not been reported to date. The data presented in this report also suggest that the number of HIV infections resulting from non-B variants in Poland is increasing. Although the HIV epidemic initially was a result of subtype $B$ infections, the rise in cases resulting from non-B variants in the recent years reflects a change in the epidemiology of this disease [Stańczak et al. 2006] and this trend parallels what has been observed in Western Europe [Geretii 2006].

Non-B subtypes have also been identified across Europe with variable prevalence, however, European data on non-B subtype cases resulting from sexual contact are commonly seen in populations with a high immigrant population or among individuals who are epidemiologically linked [Böni et al., 1999]. For example, in Germany, the circulating recombinant forms, CRF02_AG and CRF01_AE, are most commonly observed in the context of smaller subtype C and D infections [Sagir et al., 2007]. In the UK, the highest non-B prevalence was observed among black African and black Caribbean patients [Hemelaar et al., 2006], while in Spain, a high frequency of subtype G was reported [Holguín, Alvarez, Soriano, 2002].

The high frequency of non-B subtypes observed in the studied cohort might be related to the 210 fact that the study center was located in a major port city. Sailors traveling the world might have 211 imported non-B variants which spread in the local population. Indeed, the CRF13_cpx variant was 212 identified in a male sailor traveling from Africa who reported heterosexual contacts in this continent, 213 however, only in one subtype D case exposure outside Poland was reported, while review of the 214 remaining medical records of subtype D patients revealed that the infections were acquired in 215 northwestern Poland. The surprising dominance of non-clade B infections (17/21, 81\%) in heterosexuals, particularly women $(12 / 21,57 \%)$ was a novel finding. The majority of the women in 
this group never admitted to sexual promiscuity (19/21) and HIV diagnosis was unexpected for both patients and clinicians. Their unknown infection status combined with low social awareness of HIV risk factors in Poland [Izdebski 2003] and infrequent HIV testing among heterosexual individuals might explain the high number of HIV patients observed in this population. As a result, there were a large proportion of symptomatic/AIDS patients, with late diagnoses more common among individuals bearing non-B variants compared to subtype B-infected patients. This result was consistent with the reported tendency for late testing in Poland and Europe [Bander et al., 2009; Adler et al., 2009].

Since antiretroviral treatment initiation is recommended immediately in case of the late HIV diagnosis, it is important to determine the virus subtype due to its possible influence on disease transmission and progression and tropism [Geretii 2006]. This is especially important in subtype D infection cases, as observed in this study. It has been demonstrated that in clade D-infected Kenyan women the risk of death is more than two-fold higher compared to clade A-infected individuals. Moreover, depletion of CD4+ lymphocytes was more rapid in subtype D-infected patients, suggesting that disease progressed more rapidly in these patients than in non- $D$ infected patients [Baeten 2007]. This phenomenon might be related to the higher rates of the CXCR4 or mixed tropisms observed among individuals with subtype $D$ infections which and faster progression to AIDS [Kaleebu 2007]. Indeed, time to AIDS (defined as CD4 $\leq 200$ cells/ $\mu$ ) among Ugandans with subtype D infections was shorter compared to subtype A-infected individuals with a significantly higher risk of death [Kiwanuka 2007]. The nature of HIV progression rates in subtype D-infected individuals of Caucasian origin remains to be defined.

A limitation of the current study relates to the subtyping methods used. The HIV-1 genotyping platforms available at the time of the study (2.8 Viroseq HIV-1 and Trugene Genotyping systems) are used for carrying out HIV drug resistance analyses. Although both tools have been shown to be highly efficient for B clade sequencing, their detection thresholds for non-B variants is lower [Beddows 2003]. Therefore, the possibility that some variants may have gone undetected exists, however, only these detection methods were available. Moreover, the non-B subtype viral 
loads observed may be inaccurate since most viral load assays are optimized for HIV-1 B clades. This

244 limitation is currently being overcome by the real-time PCR platforms optimized for an array of the 245 most common HIV-1 subtypes and CRFs.

This study demonstrated that HIV subtypes associated with infections of Caucasians from

247 northwestern Poland were genetically diverse. It is likely that HIV non-B subtypes were acquired from 248 travelers visiting African and West European countries that spread the infection primarily via 249 heterosexual contacts. The dissemination of subtype D strains among Caucasians was identified in 250 symptomatic and AIDS-stage patients, a large majority of which were women. In general, non-B 251 subtype-infected individuals tended to be diagnosed with symptomatic infections or AIDS and these 252 patients had higher baseline viral loads and lower CD4+ lymphocyte counts compared to subtype B253 infected patients. This distribution is likely related to the low HIV testing frequency in Poland 254 [European Centre for the Epidemiological Monitoring of HIV/AIDS, 2007], especially among 255 populations traditionally not associated with risky sexual or drug use-related behavior.

In light of the increased dissemination of non-B subtypes and its impact on treatment 257 responses and disease progression, it will be important to carry out subtype analyses of strains 258 isolated from respective patients and a careful review of epidemiological data will be necessary as 259 described previously [Hemelaar et al., 2006]. Regional changes in HIV subtype distribution and 260 analysis of mutation patterns associated with transmission will play a significant role in clinical 261 management.

\section{SEQUENCE DATA}

264 HIV-1 non-B subtype sequences were submitted to the Gen Bank and may be accessed with 265 the following IDs: Subtype A: GU906861, GU906877; Subtype C: GU906868, GU906870; Subtype D: 266 GU906857, GU906858, GU906860, GU906863, GU906864, GU906865, GU906866, GU906867, 267 GU906871, GU906872, GU906873, GU906874; CRF01_AE: GU906859, GU906862, GU906869, GU906876; CRF13_cpx: GU906875. 


\section{ACKNOWLEDGEMENTS}

271 This research was funded by the Pomeranian Medical University. Viroseq 2.8 sequencing

272 assays were kindly provided by Abbott Laboratories, Poland. The authors would like to thank Mike 273 Youle for his intellectual contributions and review of the manuscript. 
274

275

276

277

278

279

280

281

282

283

284

285

286

287

288

289

290

291

292

293

294

295

296

297

298

299

\section{REFERENCES}

Adler A, Mounier-Jack S, Coker RJ. 2009. Late diagnosis of HIV in Europe: definitional and public health challenges. AIDS Care 21:284-293.

Baeten JM, Chohan B, Lavreys L, Chohan V, McClelland S, Certain L, Mandaliya K, Jaoko W, Overbaugh J. 2007. HIV-1 subtype $D$ infection is associated with faster disease progression than subtype $A$ in spite of similar plasma HIV-1 loads. J Infect Dis 195:1177-1180.

Beddows S, Galpin S, Kazmi SH, Ashraf A, Johargy A, Frater AJ, White N, Braganza R, Clarke J, McClure $M$, Weber JN. 2003. Performance of two commercially available sequence-based HIV-1 genotyping systems for the detection of drug resistance against HIV type 1 group M subtypes. J Med Virol. 70:337-42.

Bander D, Leszczyszyn-Pynka M, Boroń-Kaczmarska A. 2009. Late AIDS diagnosis in patients hospitalized in Clinic of Infectious Diseases and Hepatology PAM in years 2003-2007. Przegl Epidemiol 63:61-66.

Bocket L, Cheret A, Deuffic-Burban S, Choisy P, Gerard Y, de la Tribonnière X, Viget N, Ajana F, Goffard A, Barin F, Mouton Y, Yazdanpanah Y. 2005. Impact of human immunodeficiency virus type 1 subtype on first-line antiretroviral therapy effectiveness. Antivir Ther 10:247-254.

Böni J, Pyra H, Gebhardt M, Perrin L, Bürgisser P, Matter L, Fierz W, Erb P, Piffaretti JC, Minder E, Grob P, Burckhardt JJ, Zwahlen M, Schüpbach J. 1999. High frequency of non-B subtypes in newly diagnosed HIV-1 infections in Switzerland. J Acquir Immune Defic Syndr 22:174-179. 
300

301

302

303

304

305

306

307

308

309

310

311

312

313

314

315

316

317

318

319

320

321

322

323

324

Chaix ML, Descamps D, Harzic M, Schneider V, Deveau C, Tamalet C, Pellegrin I, Izopet J, Ruffault A, Masquelier B, Meyer L, Rouzioux C, Brun-Vezinet F, Costagliola D. 2003. Stable prevalence of genotypic drug resistance mutations but increase in non-B virus among patients with primary HIV-1 infection in France. AIDS 17:2635-2643.

Czarkowski M, Cieleba E، Dacka P, Kondej B. 2007. National Institute of Public Health - National Institute of Hygiene - Department of Epidemiology. Chief Sanitary Inspectorate - Department of Communicable Diseases Control. Infectious diseases and poisonings in Poland in 2007. Available at www.pzh.gov.pl/oldpage/epimeld.

European Centre for the Epidemiological Monitoring of HIV/AIDS. WHO and UNAIDS Collaborating Centre on HIV/AIDS. 2007. HIV/AIDS Surveillance in Europe. End-year report 2006. No. 75. Available at www.eurohiv.org/reports.

Geretti AM. 2006. HIV-1 subtypes: epidemiology and significance for HIV management. Review. Curr Opin Infect Dis 19:1-7.

Hemelaar J, Gouws E, Ghys PD, Osmanov S. 2006. Global and regional distribution of HIV-1 genetic subtypes and recombinants in 2004. AIDS 20:13-23.

Holguín A, Alvarez A, Soriano V. 2002. High prevalence of HIV-1 subtype G and natural polymorphisms at the protease gene among HIV-infected immigrants in Madrid. AIDS 16:1163-1170.

Holguín A, Ramirez de Arellano E, Rivas P, Soriano V. 2006. Efficacy of antiretroviral therapy in individuals infected with HIV-1 non-B subtypes. AIDS Rev 8:98-107. 
326

327

328

329

330

331

332

333

334

335

336

337

338

339

340

341

342

343

344

345

346

347

348

349

350

Holguín A, de Mulder M, Yebra G, López M, Soriano V. 2008. Increase of non-B subtypes and recombinants among newly diagnosed HIV-1 native Spaniards and immigrants in Spain. Curr HIV Res 6:327-334.

Holguín A, López M, Soriano V. 2008. Reliability of rapid subtyping tools compared to that of phylogenetic analysis for characterization of human immunodeficiency virus type 1 non-B subtypes and recombinant forms. J Clin Microbiol 46:3896-3899.

Izdebski Z, Małecka A. 2003. Attitudes and opinions of youth concerning HIV/AIDS problem. HIV AIDS Rev 2:115-122.

Kantor R, Katzenstein DA, Efron B, Carvalho AP, Wynhoven B, Cane P, Clarke J, Sirivichayakul S, Soares MA, Snoeck J, Pillay C, Rudich H, Rodrigues R, Holguin A, Ariyoshi K, Bouzas MB, Cahn P, Sugiura W, Soriano V, Brigido LF, Grossman Z, Morris L, Vandamme AM, Tanuri A, Phanuphak P, Weber JN, Pillay D, Harrigan PR, Camacho R, Schapiro JM, Shafer RW. 2005. Impact of HIV-1 subtype and antiretroviral therapy on protease and reverse transcriptase genotype: results of a global collaboration. PLoS Med 2:e112.

Keele BF, Van Heuverswyn F, Li Y, Bailes E, Takehisa J, Santiago ML, Bibollet-Ruche F, Chen Y, Wain LV, Liegeois F, Loul S, Ngole EM, Bienvenue Y, Delaporte E, Brookfield JF, Sharp PM, Shaw GM, Peeters M, Hahn BH. 2006. Chimpanzee reservoirs of pandemic and nonpandemic HIV-1. Science 313:523-526.

Kaleebu P, Nankya IL, Yirrell DL, Shafer LA, Kyosiimire-Lugemwa J, Lule DB, Morgan D, Beddows S, Weber J, Whitworth JA. 2007. Relation between chemokine receptor use, disease stage, and HIV-1 subtypes A and D: results from a rural Ugandan cohort. J Acquir Immune Defic Syndr 45:28-33. 
352

353

354

355

356

357

358

359

360

361

362

363

364

365

366

367

368

369

370

371

372

373

374

375

376

Kiwanuka N, Laeyendecker O, Robb M, Kigozi G, Arroyo M, McCutchan F, Eller LA, Eller M, Makumbi

F, Birx D, Wabwire-Mangen F, Serwadda D, Sewankambo NK, Quinn TC, Wawer M, Gray R. 2008.

Effect of human immunodeficiency virus Type 1 (HIV-1) subtype on disease progression in persons from Rakai, Uganda, with incident HIV-1 infection. J Infect Dis 197:707-713.

Paraskevis D, Pybus O, Magiorkinis G, Hatzakis A, Wensing AM, van de Vijver DA, Albert J, Angarano G, Asjo B, Balotta C, Boeri E, Camacho R, Chaix ML, Coughlan S, Costagliola D, De Luca A, de Mendoza C, Derdelinckx I, Grossman Z, Hamouda O, Hoepelman IM, Horban A, Korn K, Kuecherer C, Leitner T, Loveday C, Macrae E, Maljkovic I, Meyer L, Nielsen C, Op de Coul EL, Ormaasen V, Perrin L, Puchhammer-StockI E, Ruiz L, Salminen M, Schmit JC, Schuurman R, Soriano V, Stanczak J, Stanojevic M, Struck D, Van Laethem K, Violin M, Yerly S, Zazzi M, Boucher CA, Vandamme AM, Programme S. 2009. Tracing the HIV-1 subtype B mobility in Europe: a phylogeographic approach. Retrovirology 6:49.

Rambaut A, Posada D, Crandall KA, Holmes EC. 2004. The causes and consequences of HIV evolution. Nat Rev Genet 5:52-61.

Ramirez-Piedad MK, Lepej SZ, Yerly S, Begovac J. 2009. High prevalence of non-B HIV-1 subtypes in seamen and their sexual partners in Croatia. J Med Virol 81:573-577.

Sagir A, Oette M, Kaiser R, Däumer M, Fätkenheuer G, Rockstroh JK, Knechten H, Schmutz G, Hower M, Emmelkamp J, Pfister H, Häussinger D. RESINA Study Team. 2007. Trends of prevalence of primary HIV drug resistance in Germany. J Antimicrob Chemother 60:843-848. 
Stańczak GP, Stańczak JJ, Firlag-Burkacka E, Wiercińska-Drapało A, Leszczyszyn-Pynkad M, 378 Jabłonowska E, Małolepsza E, Horban A. 2007. Transmission of HIV-1 drug resistance among newly 379 diagnosed patients in Poland. Przegl Epidemiol 61:29-34.

380

381 Taylor BS, Hammer SM. 2008. The challenge of HIV-1 subtype diversity. N Engl J Med 359:1965-1966.

383 Thomson MM, de Parga EV, Vinogradova A, Sierra M, Yakovlev A, Rakhmanova A, Delgado E, Casado 384 G, Muñoz M, Carmona R, Vega Y, Pérez-Alvarez L, Contreras G, Medrano L, Osmanov S, Nájera R. 385 2007. New insights into the origin of the HIV type 1 subtype A epidemic in former Soviet Union's 386 countries derived from sequence analyses of preepidemically transmitted viruses. AIDS Res Hum 387 Retroviruses 23:1599-1604.

388

389 Van Heuverswyn F, Li Y, Neel C, Bailes E, Keele BF, Liu W, Loul S, Butel C, Liegeois F, Bienvenue Y, 390 Ngolle EM, Sharp PM, Shaw GM, Delaporte E, Hahn BH, Peeters M. 2006. Human immunodeficiency 391 viruses: SIV infection in wild gorillas. Nature 444:164.

392 
393

394

395

396

397

398

399

400

401

402

403

404

405

406

407

408

409

410

411

412

413

Figure Legends

Fig. 1. Neighbor-joining analysis. Neighbor-joining tree showing phylogenetic relationships of subtype

$B(A)$ and non-subtype $B(B)$ isolates to the HIV-1 M group reference strains. Bootstrap values $>700$ are listed at the base of each branch. Subtype for each reference isolate are indicated on external nodes. From the final version of the phylogenetic tree reference CRFs sequences for the variants not observed in this study were removed.

Fig. 2. HIV subtype characterization. HIV-1 M subtype and CRF assignment by phylogenetic analysis (A), the REGA genotyping tool 2.0 (B) or the Stanford HIV drug resistance database (C).

Fig. 3. Phylogenetic tree reconstruction. Each patient was coded with a unique identifier and their respective isolates analyzed based on HIV-1 protease and reverse transcriptase sequences. HIV-1 variants are indicated to the right. Bootstrap values (1000 sets) are indicated if above 700 . Branch length reflects evolutionary distance. Clusters of patients with similar exposure modes are circled. MSM, Men who have sex with men; IDU, Injection drug users; HET, heterosexual transmissions.

Fig. 4. Baseline CD4+ lymphocyte counts in the analysed groups. Each symbol represents the number of CD4+ cells/ $\mu$ l from either HIV-1 B or non-B subtype-infected individuals.

Figure 5. Baseline HIV-1 viral loads in the analysed groups Each symbol represents the number of copies/ml from either HIV-1 B or non-B subtype-infected individuals. 


\section{Page 27 of 29}

Journal of Medical Virology

414 Table I. Subtype-based characteristics of the study population.

415

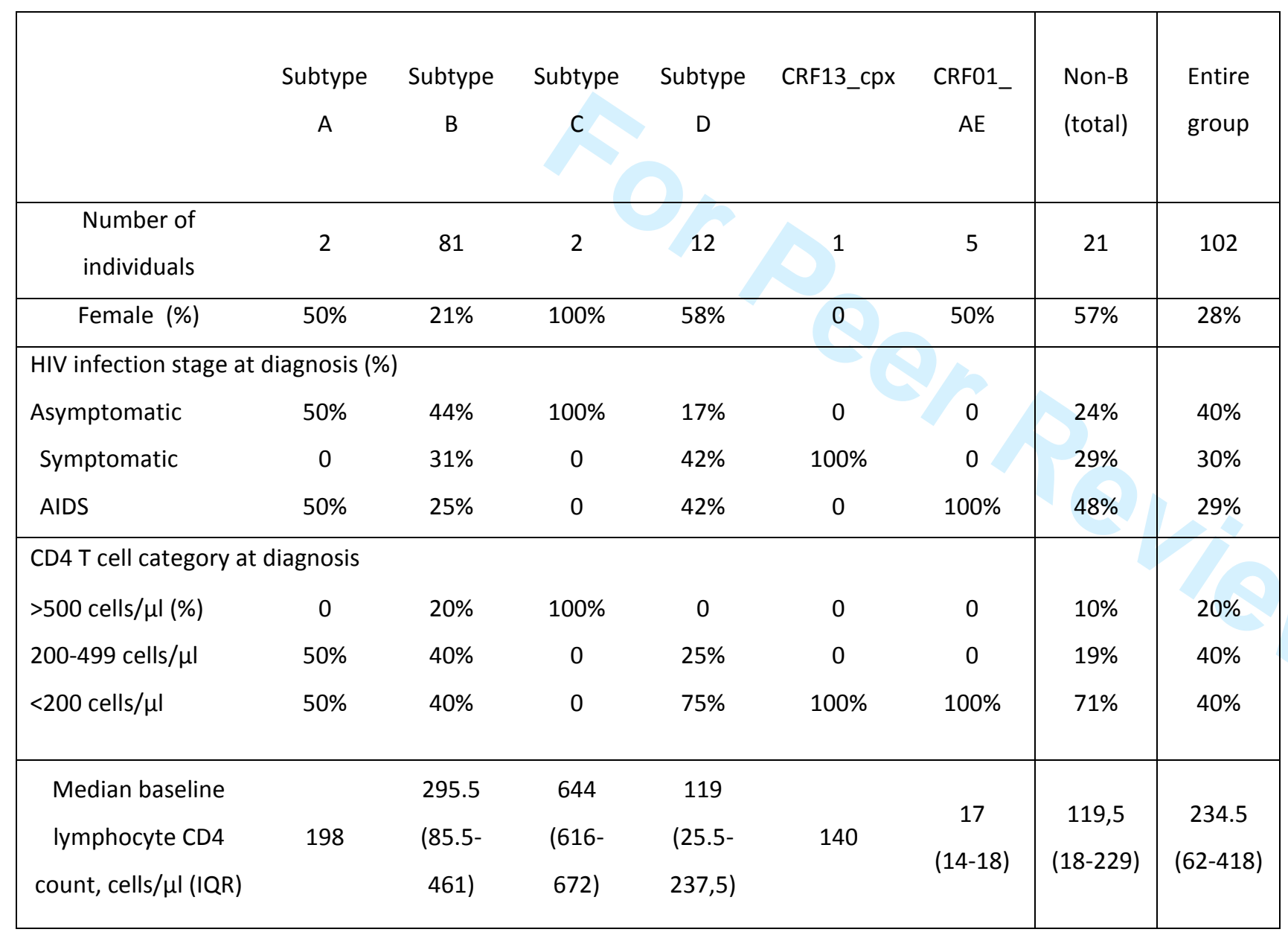




\begin{tabular}{|c|c|c|c|c|c|c|c|c|}
\hline $\begin{array}{l}\text { Median baseline } \\
\text { viral load }^{1} \\
\text { copies/ml (IQR) }\end{array}$ & $\begin{array}{c}\text { Not } \\
\text { available }\end{array}$ & $\begin{array}{r}95,300 \\
(21,200- \\
435,000)\end{array}$ & $\begin{array}{r}34,450 \\
(25,675- \\
43,225)\end{array}$ & $\begin{array}{r}370,000 \\
(180,000- \\
480,000)\end{array}$ & $\begin{array}{c}\text { Not } \\
\text { available }\end{array}$ & $\begin{array}{l}390,000 \\
(96,500- \\
590,000)\end{array}$ & $\begin{array}{l}275,000 \\
(76,900- \\
507,500)\end{array}$ & $\begin{array}{l}100,000 \\
(24,800- \\
480,000)\end{array}$ \\
\hline $\begin{array}{c}\text { Mean age at the } \\
\text { diagnosis, years } \\
\text { (range) }\end{array}$ & $\begin{array}{c}29 \\
(18-40)\end{array}$ & $\begin{array}{c}38.2 \\
(23-67)\end{array}$ & $\begin{array}{c}29 \\
(28-30)\end{array}$ & $\begin{array}{c}44.6 \\
(32-60)\end{array}$ & 45 & $\begin{array}{c}34.8 \\
(21-54)\end{array}$ & $\begin{array}{c}40.9 \\
(26-60)\end{array}$ & $\begin{array}{c}38.7 \\
(23-67)\end{array}$ \\
\hline \multicolumn{9}{|l|}{ Transmission route } \\
\hline IDU & $100 \%$ & $35 \%$ & 0 & 0 & 0 & $50 \%$ & $19 \%$ & $31 \%$ \\
\hline Heterosexual & 0 & $15 \%$ & $100 \%$ & $100 \%$ & $100 \%$ & $50 \%$ & $81 \%$ & $28 \%$ \\
\hline MSM & 0 & $42 \%$ & 0 & 0 & 0 & 0 & 0 & $33 \%$ \\
\hline Mixed $^{2}$ & 0 & $9 \%$ & 0 & 0 & 0 & 0 & 0 & $7 \%$ \\
\hline
\end{tabular}

$416{ }^{1}$ Baseline viral loads available for $51 / 102$ patients (50\%). 39/81 (48\%) patients presented with subtype B infections and $12 / 21$ (57\%) patients presented with 417 non-B clade infections.

$418{ }^{2}$ Mixed route of transmission was assigned for individuals with probable infections from exposures resulting from either intravenous drug use (IDU)/men 419 having sex with men (MSM) or from MSM/heterosexual exposure 
